\title{
O EDUCADOR AMBIENTAL DO PROJETO CULTIVANDO ÁGUA BOA DA BACIA HIDROGRÁFICA DO PARANÁ III ${ }^{1}$
}

\author{
Luzia Klunk ${ }^{2}$ \\ Jane Márcia Mazzarino³ \\ Luciana Turatti ${ }^{4}$
}

Resumo: A educação baseada na participação e que valoriza práticas culturais locais fundamenta a Política Nacional de Educação Ambiental (PNEA) e a prática educativa do sujeito ecológico. O objetivo deste artigo é identificar elementos que constituem o sujeito ecológico no Programa Cultivando Água Boa (CAB) por meio das práticas dos seus educadores ambientais. Utilizou-se a pesquisa bibliográfica para conceituar a Educação Ambiental, a pesquisa documental para caracterizar o $\mathrm{CAB}$, bem como observações e entrevistas para identificar os elementos que compõem o perfil dos educadores ambientais do $\mathrm{CAB}$. Os resultados apontam que a formação e a motivação para desenvolver ações de Educação Ambiental locais atravessam os modos de fazer destes atores que atuam no CAB.

Palavras-chave: Educação Ambiental; Sujeito Ecológico; Água; Estudo Qualitativo.

${ }^{1} \mathrm{O}$ presente trabalho foi realizado com apoio da Coordenação de Aperfeiçoamento de Pessoal de Nível Superior - Brasil (CAPES) - Código de Financiamento 001.

2 Universidade do Vale do Taquari. E-mail: luzia.klunk@univates.br

3 Universidade do Vale do Taquari. E-mail: janemazzarino@univates.br

${ }^{4}$ Universidade do Vale do Taquari. E-mail: lucianat@univates.br 


\section{Introdução}

As conferências mundiais sobre ambiente e sociedade (Estocolmo, na Suécia, em 1972; Belgrado, na lugoslávia, em 1975; Tbilisi, na Geórgia, em 1977; Moscou, na Rússia, em 1987; Rio de Janeiro, no Brasil, em 1992; Tessalônica, na Grécia, em 1997; Johannesburgo, na África do Sul, em 2002; Rio de Janeiro, no Brasil, em 2012) oportunizaram a criação de políticas públicas em Educação Ambiental voltadas para a aprendizagem do cidadão num contexto de construção de uma ética ecológica planetária. Acompanhando o cenário mundial, no Brasil, em 1971 cria-se a Secretaria Especial do Meio Ambiente; em 1981, a Política Nacional do Meio Ambiente; em 1990, o Fundo Nacional de Meio Ambiente, seguido, um ano depois, pela criação do Grupo de Trabalho de Educação Ambiental do Ministério da Educação e a Divisão de Educação Ambiental do Instituto Brasileiro de Meio Ambiente e dos Recursos Naturais Renováveis. Em 1992, cria-se o Ministério do Meio Ambiente; em 1993, o grupo de trabalho é transformado em Coordenação Geral de Educação Ambiental e surge o Programa Nacional de Educação Ambiental. Em 1996, é publicada a Lei de Diretrizes e Bases da Educação Nacional e, em 1997, os Parâmetros Curriculares Nacionais incluem a Educação Ambiental como tema transversal. Em 1999, inicia-se a implantação do Sistema Brasileiro de Educação Ambiental e a Política Nacional de Educação Ambiental (PNEA).

Os documentos nacionais e as diretrizes nacionais e globais salientam a importância da educação dialógica para o processo de construção de uma sociedade pautada por patamares civilizacionais que tenham a sustentabilidade e a atuação política consciente como seu cerne. Impõe-se, portanto, uma responsabilidade ético-política de reflexão e ação sobre a realidade que cabe aos educadores ambientais que atuam nas comunidades.

O objetivo deste artigo é identificar elementos que constituem o sujeito ecológico no Programa Cultivando Água Boa (CAB) por meio das práticas dos seus educadores ambientais. Utilizou-se a pesquisa bibliográfica para conceituar a Educação Ambiental, a pesquisa documental para caracterizar o $\mathrm{CAB}$ (site, cartilhas, vídeos institucionais), bem como observações diretas e entrevistas.

Foram selecionados informantes considerados representativos da população-alvo sobre a qual se buscou aprofundar conhecimentos. As entrevistas ocorreram com participantes de Toledo e de Cascavel, locais em que o programa está mais fortalecido ${ }^{5}$. Os representantes de Itaipu Binacional indicaram gestores de Educação Ambiental $\left(\mathrm{PAP}^{6}\right.$ ) atuantes no programa,

\footnotetext{
${ }^{5}$ Foz do Iguaçu também foi indicado pelos representantes de Itaipu Binacional, onde o processo está enraizado, porém está mais distante geograficamente.

${ }^{6}$ A sigla PAP indica pessoas que aprendem participando por meio de pesquisa-ação-participante, em que PAP1 são os idealizadores da metodologia (Ministério da Educação e Ministério do Meio Ambiente), PAP2 são os integrantes do Coletivo Educador, gestores de educação ambiental dos municípios da bacia hidrográfica, PAP3 são os educadores ambientais e PAP4 são os membros das comunidades de aprendizagem, onde os educadores ambientais aplicam os conhecimentos adquiridos na Formação em Educação Ambiental (FEA) do CAB.
}

revista brasileira educação ambiental 
que, por sua vez, sugeriram outros gestores e também educadores ambientais (PAP3) que efetivam ações nos seus municípios. Foram realizadas quatro entrevistas com gestores de Educação Ambiental de Toledo e quatro de Cascavel; seis com educadores ambientais em cada um desses municípios; três com funcionários de Itaipu Binacional, e, ainda, com a diretora da empresa atuante no CAB (Nativa Socioambiental) e com duas pessoas que auxiliaram na construção do programa. Além disso, foram realizadas observações diretas em quatro momentos: nos pré-encontros do CAB em Itaipulândia e Marechal Cândido Rondon, no encontro anual em Foz do Iguaçu, no processo de formação em Santa Helena e durante a atuação do educador ambiental na comunidade de aprendizagem.

Os dados foram tratados por meio da análise de conteúdo qualitativa, que sintetiza, descreve e interpreta os materiais de forma aprofundada, baseada na eleição de categorias (BARDIN, 1977; MORAES, 2007).

\section{O conceito de Educação Ambiental}

Na década de 1990, surgem várias denominações para conceituar a Educação Ambiental: alfabetização ecológica, educação para a sustentabilidade, ecopedagogia, Educação Ambiental crítica, transformadora e emancipatória; educação no processo de gestão ambiental, Educação Ambiental libertadora, Educação Ambiental conservadora, entre outras. Todas buscam a construção de processos de sustentabilidade a partir do viés educativo (ZAKRZEVSKI, 2003). A expressão Educação Ambiental é usada, neste artigo, de forma ampla, como um processo de aprendizagem para a cidadania e a sustentabilidade, baseada na reflexão e na criticidade acerca das relações entre sociedade e natureza. A Política Nacional de Educação Ambiental trabalha com o viés crítico, transformador e emancipatório, baseada na participação, na motivação e na reflexão e valoriza práticas culturais locais. Esta Educação Ambiental pode ser caracterizada, ainda, como cidadã. A educação para a cidadania possibilita motivar e sensibilizar a participação da sociedade e para ampliação do controle social da coisa pública (JACOBI, 2003).

Segundo Jacobi (2005), a educação para a participação depende da gestão baseada na garantia do acesso à informação e na consolidação de canais abertos de participação, sendo que o acesso à informação passa pelo incremento dos meios, com o papel indutivo do poder público nos conteúdos educacionais e informativos. Já as práticas emancipatórias são norteadas pelo empoderamento e pela justiça social, devendo "apontar para propostas pedagógicas centradas na mudança de hábitos, atitudes e práticas sociais, desenvolvimento de competências, capacidade de avaliação e participação dos educandos" (JACOBI, 2005, p. 241).

Nesse sentido, Sorrentino (1998) entende que o educador ambiental tem o desafio de resgatar o desenvolvimento de valores e comportamentos, como confiança, respeito mútuo, responsabilidade, compromisso, solidariedade e iniciativa, e estimular uma visão global e crítica das questões ambientais, com um enfoque interdisciplinar e voltado para reconstrução de saberes. Tristão Revbea, São Paulo, V. 13, № 3: 10-25, 2018. 
(2002), por sua vez, pontua quatro desafios para a Educação Ambiental: 1) enfrentar a multiplicidade de visões; 2) superar a visão do especialista; 3) superar a pedagogia das certezas; 4) superar a lógica da exclusão e das desigualdades sociais. Diante disso, Carvalho propõe pensar o educador ambiental como um mediador-intérprete.

A EA fomenta sensibilidades afetivas e capacidades cognitivas para uma leitura do mundo do ponto de vista ambiental. Dessa forma, estabelece-se como mediação para múltiplas compreensões da experiência do indivíduo e dos coletivos sociais em suas relações com o ambiente. Esse processo de aprendizagem por via dessa perspectiva de leitura dá-se particularmente pela ação do educador como intérprete dos nexos entre sociedade e ambiente e da EA como mediadora na construção social de novas sensibilidades e posturas éticas diante do mundo (CARVALHO, 2012, p. 79 e 80).

Sensibilidades estas que para Boff (2002, p. 239) dependem do "resgate de valores da solidariedade, da inclusão e da reverência; superação do conceito fechado de desenvolvimento sustentável; e ética do cuidado". Portanto, a Educação Ambiental deve buscar, além de gerar aprendizagens sensíveis, compreender as relações entre a sociedade e a natureza e intervir nos problemas e conflitos ambientais, contribuindo para uma mudança de valores e atitudes, formando um sujeito capaz de identificar e problematizar as questões socioambientais e agir sobre elas (CARVALHO, 2012).

A Educação Ambiental que enfatiza aspectos comunitários e populares tende a identificar conflitos e problemas concernentes às relações das populações com seu entorno, buscando melhorar as condições ambientais e valorizar as práticas culturais locais, gerando, assim, maior capacidade para resolver problemas, para pensar as consequências ambientais das escolhas coletivas e para decidir sobre a qualidade de vida das populações. É uma aprendizagem que ultrapassa a fronteira entre práticas formais e não-formais (CARVALHO, 2012).

Essa Educação Ambiental, que está baseada na motivação, no posicionamento crítico, no acesso à informação, na coparticipação para identificação de problemas socioambientais, na definição de objetivos e soluções de forma conjunta e como prática integrativa e dialógica, gera empoderamento dos atores sociais por ser democrática. Para Freire (2002) a educação para a democracia é um meio para a transformação da sociedade, pois baseia-se na participação ativa do sujeito no processo educativo.

A educação libertadora proposta por Freire tem viés e é fundamentada no diálogo problematizador. Busca a libertação porque não aceita nem o homem isolado do mundo nem o mundo sem o homem, primando por relações dialéticas entre sujeito e realidade (FREIRE, 2002). Para Loureiro, a educação pode contribuir para o 
[...] processo de construção de uma sociedade pautada por novos patamares civilizacionais e societários distintos dos atuais, na qual a sustentabilidade da vida, a atuação política consciente e a construção de uma nova ética que se afirme como ecológica sejam seu cerne (LOUREIRO, 2006, p. 90).

Segundo ele, uma Educação Ambiental que assume o caráter emancipatório é construída em contextos coletivos de aprendizagem baseados na dialogia, no exercício da cidadania, na compreensão do mundo em sua complexidade e da vida em sua totalidade, o que depende dos modos de interação entre os sujeitos e de práticas transversais entre as diversas áreas.

\section{O educador ambiental como sujeito ecológico}

O educador ambiental que internaliza os princípios da Educação Ambiental, passa a estendê-los a todas as esferas da sua vida, adotando tanto uma conduta individual como uma responsabilidade ético-política de reflexão e ação sobre a realidade complexa, transformando-se em um sujeito ecológico (CARVALHO, 2000, 2012).

Motivado pela paixão, pela busca de conhecimento e pela manifestação de vida (SATO, 2000), o sujeito ecológico possui uma matriz simbólica na contracultura da década de 1960 e 1970, marcada por um habitus ecológico e pela tradição ambiental. A contracultura foi um movimento que questionava normas institucionalmente reconhecidas pelas sociedades, fundamentadas no individualismo e no consumismo e guiadas pela lógica do mercado (CASTELLS, 2001).

O sujeito ecológico tem uma bagagem de experiência em decorrência de seus pertencimentos, ora no ativismo ecológico, ora na militância política das lutas em movimentos sociais e, também, do mundo da ação política profissionalizada, que cresceu a partir das Organizações Não Governamentais (ONGs) de desenvolvimento social (CARVALHO, 2000).

O sujeito ecológico pode ser compreendido como um educador popular no que se refere ao caráter mobilizador que ele provoca. $O$ educador popular apresenta as seguintes características:

[...] o sentimento de pertença ao grupo, o compromisso com um projeto emancipatório e, por último, a responsabilidade na implicação de todos como potencial de agrupamento e articulação das classes populares em movimentos. [...] Carregam consigo desejos de uma sociedade em que caibam todos de fato e de direito (STRECK et al, 2014, p. 86). 
rompe com essa perspectiva, já que refere-se a um ser criador, produzido a partir da experiência individual e em seu meio-ambiente social. Experiência, esta, que é constituída por sensações, emoções e interpretações, um processo inédito e único. Uma experiência acontece, alcança e apodera-se do sujeito, transformando-o (HEIDEGGER, 1987; JARA HOLLIDAY, 2006).

Fazer uma experiência quer dizer, portanto, deixar-nos abordar em nós próprios pelo que nos interpela, entrando e submetendo-nos a isso. Podemos ser assim transformados por tais experiências, de um dia para o outro ou no transcurso do tempo (HEIDEGGER, 1987, p. 143).

O sujeito da experiência se propõe à entrega, se expõe. A experiência é aquilo que toca ou que acontece e que, ao passar, transforma. Somente o sujeito da experiência está aberto a sua própria transformação. "O saber de experiência se dá na relação entre o conhecimento e a vida humana. $O$ acontecimento é comum, mas a experiência é para cada qual sua, singular e de alguma maneira impossível de ser repetida" (LARROSA BONDÍA, 2002, p. 27).

Parece-nos que é a experiência que transforma um indivíduo em sujeito. Para Touraine (1999), o processo de subjetivação ocorre quando a pessoa se liberta das forças que impedem sua autoconstrução, passando a reinventar suas práticas e transformando a sociedade. O indivíduo é uma unidade particular, em que se misturam a vida e o pensamento, a experiência e a consciência. O sujeito é a passagem do indivíduo ao ator, o qual dá sentido pessoal às experiências vividas. $O$ ator se insere nas relações sociais, transformando-as. Ou seja, o sujeito é um ser ativo e crítico, uma evolução do indivíduo, pois este é passivo e aceita as regras impostas sem questioná-las. Já o ator/agente é aquele que, além de tornar-se sujeito de si mesmo, busca modificar o meio material e social no qual está inserido.

Portanto, o agente é um ser tocado e entregue, disposto a agir em prol da cidadania, da participação social e da vida em todas as dimensões, podendo atuar como sujeito ecológico e/ou educador popular.

\section{O Programa Cultivando Água Boa}

O Programa Cultivando Água Boa surgiu em 2003 e tem como objetivo implementar a Educação Ambiental nas comunidades por ele abrangidas. Desenvolve-se na Bacia Hidrográfica do Paraná III, estado brasileiro do Paraná, envolvendo 29 municípios, cada um deles com um Comitê Gestor institucionalizado (CAB, 2018). A Figura 1 indica alguns municípios que centralizam encontros e atividades. 


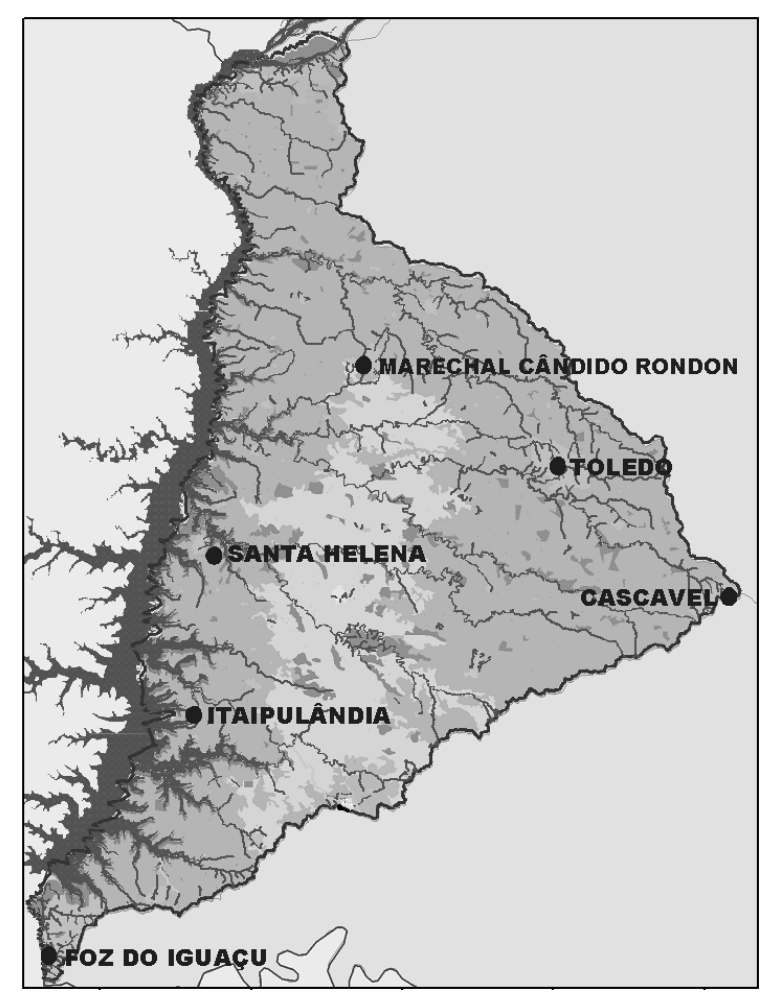

Figura 1: Bacia Hidrográfica do Paraná III, área de atuação do CAB.

Fonte: Autora a partir do Instituto das Águas do Paraná (2016).

O programa conta com parceiros do setor público, privado e da sociedade civil. Os principais programas desenvolvidos são: Plantas medicinais; Coleta solidária; Educação Ambiental; Gestão por bacias hidrográficas; Comunidades indígenas; Produção de peixes; Desenvolvimento rural sustentável; e Valorização do patrimônio regional. No programa de Educação Ambiental o CAB aplica o Programa de Formação de Educadores Ambiental (PROFEA), proposto pelo Ministério do Meio Ambiente e Ministério da Educação. Seguindo esta política nacional, sua Formação de Educadores Ambiental (FEA) compreende três instâncias: a) Coletivos Educadores representantes de diversos segmentos da sociedade e gestores de Educação Ambiental nomeados por cada um dos 29 municípios da bacia hidrográfica que planejam a formação; b) educadores ambientais - atores sociais que realizam a formação; e c) comunidades de aprendizagem - locais em que os educadores ambientais multiplicam os saberes ambientais adquiridos na formação (CAB, 2018).

O FEA se utiliza de uma mandala (FIGURA 2) para retratar o modelo de aprendizagem circular ou círculos de aprendizagem, uma metodologia integradora de pessoas, saberes e ações, em que as pessoas aprendem participando por meio de pesquisa-ação-participante (PAP) ${ }^{7}$. 


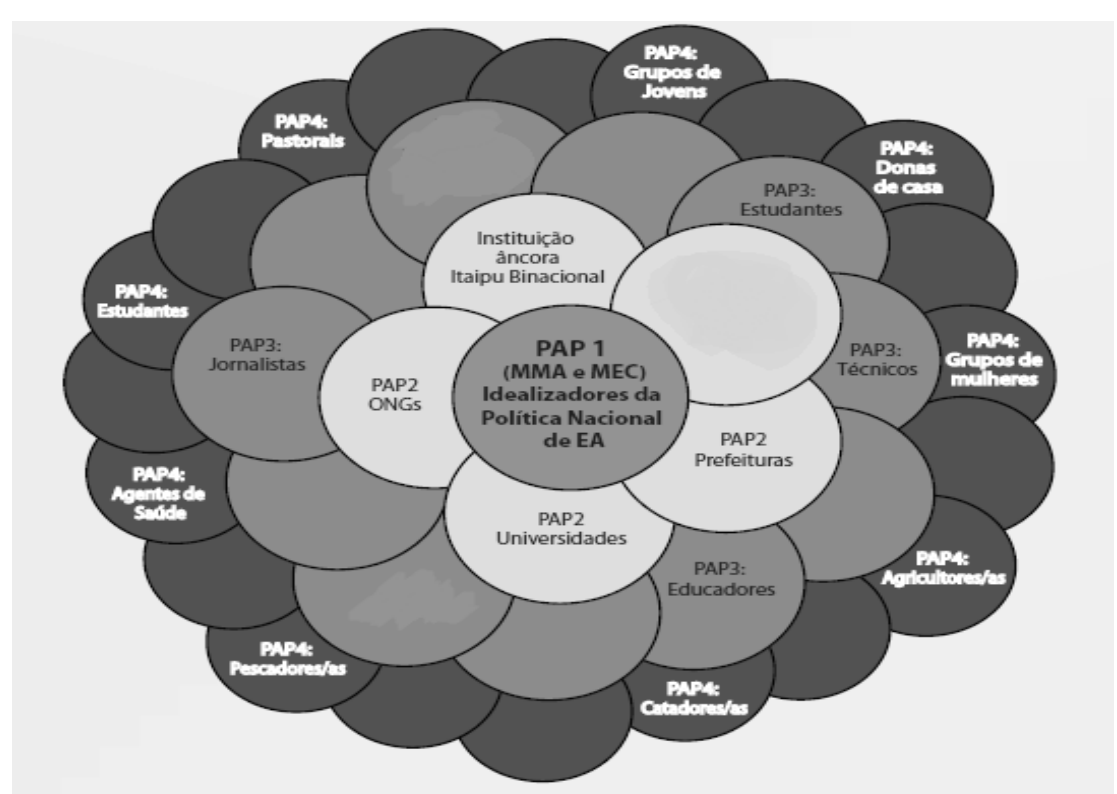

Figura 2: Mandala simbolizando aprendizagem circular do CAB.

Fonte: Autora a partir de Viezzer (2007).

O programa realiza anualmente o Pré-CAB, uma reunião dos representantes dos grupos para a avaliação e planejamento; e o Encontro do $\mathrm{CAB}$, que compreende palestras técnicas, relatos de ações e apresentações culturais locais, além de encontros para formação e aperfeiçoamento dos educadores ambientais (CAB, 2018).

\section{O educador ambiental do Projeto Cultivando Água Boa}

As entrevistas com os educadores ambientais atuantes no $C A B$ permitiram a realização de aproximações entre o perfil teoricamente construído para o sujeito ecológico e as ações por estes desenvolvidas que emergiram de seus depoimentos e das observações nas ações: formação; motivação; proximidade e continuidade.

Com relação ao perfil profissional e acadêmico dos entrevistados, percebe-se uma tendência ao pertencimento a determinadas áreas do conhecimento, notadamente ambientais e pedagógicas. No Gráfico 1 observase a área de formação acadêmica dos entrevistados, sendo a maioria biólogos.

Além da graduação, quatro entrevistados possuem pós-graduação na área de Educação Ambiental. Também se verificaram titulações de pósgraduações, entre os entrevistados, nas áreas de comunicação e ciências sociais, parapsicologia e plantas medicinais, educação e direito ambiental. 
Gráfico 1: Área de formação acadêmica dos entrevistados.

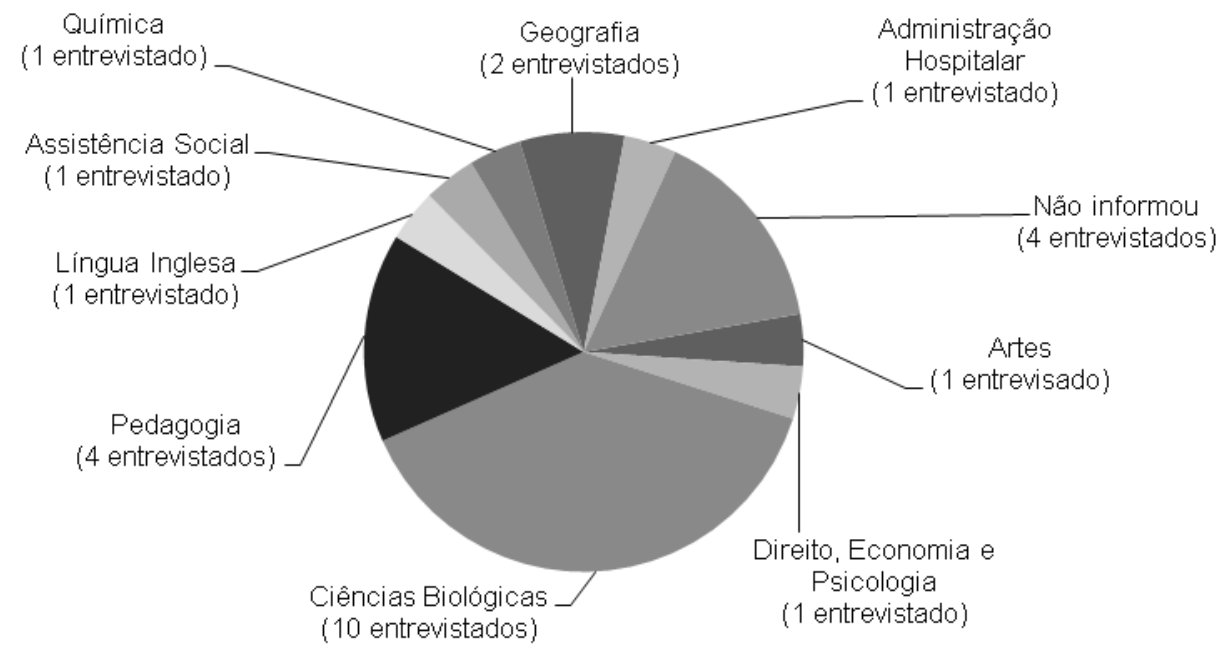

Fonte: Autora.

No depoimento de $E A C 4^{8}$ fica perceptível que o $C A B$ atrai pessoas que já atuam próximo à Educação Ambiental.

Eu sou professora de ciências então já existe uma paixão pela EA por natureza, por criação, sou filha de agricultores e sempre gostei dessa área, da preservação, da ecologia e do meio ambiente e enquanto professora sempre desenvolvi projetos de EA nas escolas onde atuei e há oito anos atrás eu fui convidada a participar.

No Gráfico 2 observam-se que os entrevistados estão vinculados profissionalmente a organizações públicas, privadas e da sociedade civil organizada, que tem ações de educação e ambientais onde os entrevistados trabalham na interface dessas duas áreas.

Os educadores ambientais do $C A B$ tendem a se envolver no programa devido a valores ambientais e sociais internalizados, por seu histórico de vida, pela formação, por influência do trabalho que desenvolvem e por influências familiares. Além disso, o CAB tende a aproximar pessoas que têm interesses afins e já tem histórico de transformação do meio em que atuam.

8 Utilizou-se das seguintes siglas para identificar as pessoas entrevistadas: AC (ajudaram na construção); FI (funcionário de Itaipu); NA (Nativa Ambiental); GEAC (gestor de educação ambiental de Cascavel); GEAT (gestor de educação ambiental de Toledo); EAC (educador ambiental de Cascavel); EAT (educador ambiental de Toledo).

Revbea, São Paulo, V. 13, № 3: 10-25, 2018. 
Gráfico 2: Instituição a que os entrevistados estão vinculados profissionalmente.

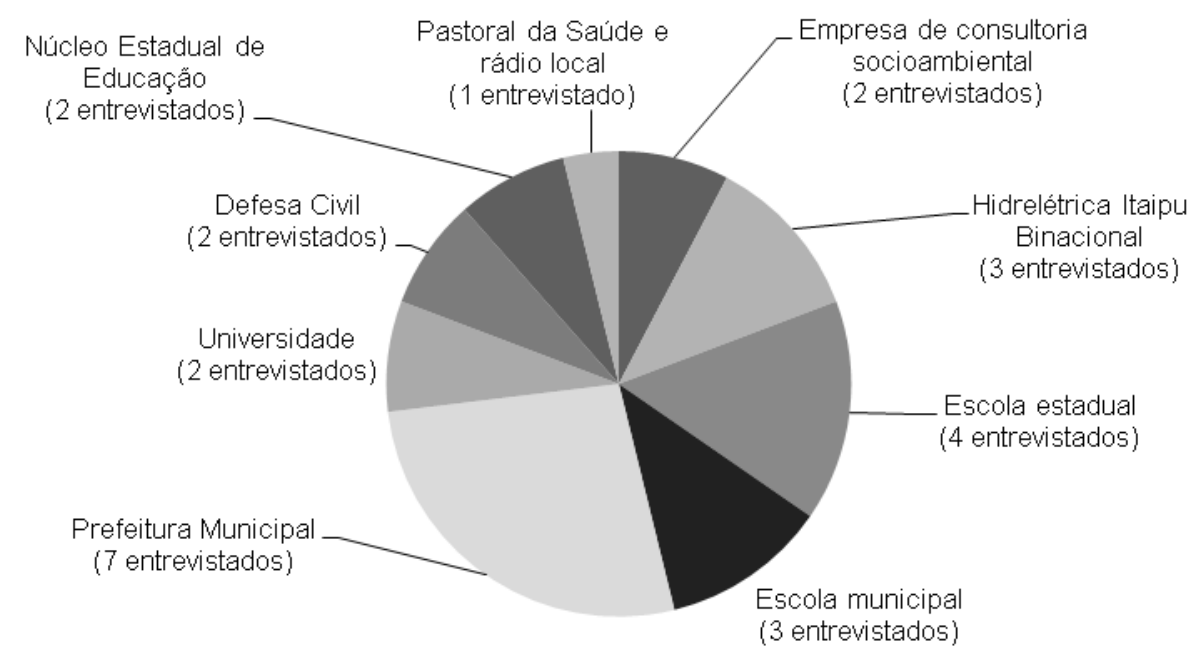

Fonte: Autora.

Com relação à motivação, percebeu-se que ela apareceu em diversos formatos: às vezes mais vinculada à transformação, outras vezes ligada ao afeto pelo território ou pela vida, como um fator emocional intrínseco ou como um compromisso intergeracional.

A motivação está presente, por exemplo, na fala da entrevistada $A C 2$, que ajudou na construção do CAB. Ela referiu que a seduz a possibilidade de transformar.

Acreditar que o meu trabalho vai transformar também, que vai propiciar que o outro também desperte, já que não podemos falar que ninguém conscientiza ninguém, a gente sensibiliza pelo conhecimento, saber como a natureza funciona, precisamos cuidar do que a gente consome, produz de resíduos.

Uma educadora ambiental que atua no $C A B$ a partir de ações desenvolvidas na escola, foi enfática ao afirmar: "Eu acredito que a educação transforma um país, e que a escola é pivô dessa transformação". Após relatar as atividades em que está envolvida, disse que o faz por "vontade e o carinho", que é sua "vontade de transformar num mundo melhor" (GEAC2). Já a entrevistada EAT6 citou o afeto ao território como elemento motivador.

Vontade do nosso ambiente estar em uma qualidade de vida melhor para todos nós, de cuidar o mundo que vivemos e do ninho de casa familiar a gente partiu para a sociedade [...] está no meu sangue, eu amo essa cidade, eu amo meu estado [...] tudo que diz respeito a natureza está interiorizado em mim e eu faço isso sem esforço. Quando se faz o que gosta, eu estou trabalhando por lazer.

Revbea, São Paulo, V. 13, № 3: 10-25, 2018.

revista brasileira educação ambiental 
$O$ afeto pela vida em todas as suas formas também surgiu como elemento motivador em diversos depoimentos. GEAC3, por exemplo, salientou "que a água pode acabar, então quando você começa a perceber que isso é real que você acredita nisso, que você pode de certa forma ajudar nem que seja mudando a consciência de uma pessoa já é válido". GEAC4, nesse aspecto, considera a alteridade e a cooperação como valores para uma vida mais integrativa.

Tanto para a vida pessoal como a vida a qual nós temos. É uma questão de propósito mesmo. Então eu trabalho em todas as frentes possíveis para deixar um planeta e um mundo melhor. Uma vida mais amorosa, mais fraterna, de paz. Que as pessoas pensem que elas fazem parte dessa teia da vida e não que estão disputando entre si.

A motivação também surge a partir de um fator emocional intrínseco. GEAT1 pensa que "vem do coração, gostar dessa área, querer fazer a diferença dentro da Educação Ambiental". Todos entrevistados percebem um voluntariado e um prazer no desenvolvimento de suas atividades. EAC4 percebe que "quem é militante na Educação Ambiental trabalha por amor à camisa". A motivação está relacionada também à incorporação de valores ecológicos como atestam diversos depoimentos nesse sentido.

[...] a gente tem aquela vontade de mudar o mundo, e como a gente não consegue mudar 0 mundo a gente muda um pedacinho. Mas eu acho que continuar mudando as coisas realmente tentando buscar um mundo melhor mais justo, com melhor qualidade de vida para as pessoas. Eu acho que é isso que me motiva (EAC6).

EAC1 falou que sempre teve interesse pelo meio ambiente, acha que aqueles que trabalham com plantas medicinais "tem isso dentro dele". EAC2, por sua vez, referiu: "às vezes dizem que eu sou uma bobona, mas o que seria do mundo se não tivessem os bobões que se envolvessem". Já EAT1 pensa que "só pode fazer isso quando acredita em uma transformação" e que se "não tivesse a utopia de um mundo melhor" já tinha desistido. O compromisso intergeracional é outro ponto que motiva os educadores ambientais. EAT4 salientou:

A gente sempre espera ter um mundo melhor, deixar para os nossos filhos, para as futuras gerações e se a gente cruzar os braços eu sei que o pouco que a gente faz não vai mudar o mundo mas se todo mundo fizer alguma coisa ou pelo menos sensibilizar as pessoas e eu acho que é muito importante isso. 
Esses depoimentos apontam que a motivação decorre do fato dos educadores ambientais entrevistados estarem emocionalmente envolvidos com a causa. Esta motivação é o elemento fundante do sujeito ecológico, que leva consigo suas crenças socioambientais, pois acredita internamente (CARVALHO, 2012).

A capacidade de aproximar pessoas de uma comunidade também são características dos educadores ambientais do CAB. Esta proximidade refere-se às ações locais desenvolvidas entre atores e suas articulações, que são elementos comuns entre os entrevistados. A interação entre os sujeitos e a inclusão, valorizando-se os diversos saberes é um elemento característico da Educação Ambiental (BOFF, 2002; JACOBI, 2003; LOUREIRO, 2006; SORRENTINO, 1998; TRISTÃO, 2002). Trata-se de uma herança da educação popular, que se propõe, assim, a empoderar sujeitos para a participação social (CARVALHO, 2012; STRECK et al, 2014).

O CAB proporciona momentos de trocas entre os educadores ambientais que demonstraram estarem articulados. GEAT1, quando referiu a aproximação que o CAB proporciona, afirmou: "você aprofunda muito as discussões e as reflexões, você convive com pessoas de diferentes setores e você começa a conhecer e vivenciar o que essas outras pessoas fazem e aplicam nas suas funções". Em seu depoimento EAT1 salientou as articulações que já realizou para desenvolver as atividades na sua comunidade de aprendizagem: com a Campanha da Fraternidade da Igreja Católica, bem como com professores de outras disciplinas da escola onde atua. EAT3, por sua vez, citou que a sua inserção em atividades do CAB a leva a buscar parcerias.

A gente coloca: eu vou estar fazendo tal coisa na minha comunidade, será que você pode me ajudar? Tem muito dessas trocas e aqui em Toledo a gente faz muitas atividades assim: semana do meio ambiente, dia mundial da água, essas datas alusivas a gente senta e programa e cada comunidade de aprendizagem se compromete de fazer alguma ação dentro da sua própria comunidade voltado para aquele tema e a nível municipal junta todos em uma ação só.

Assim, as ações de Educação Ambiental do CAB buscam uma proximidade com a comunidade que faz despertar nos educadores a capacidade de aproximar pessoas. Entre os funcionários da Itaipu que trabalham no CAB esta característica articuladora advém da forte afinidade do programa com a educação popular. A coordenadora de Educação Ambiental do $\mathrm{CAB}$ referiu que tinha "proximidade com os agricultores, porque eu sempre morei, então eu tinha muita facilidade de chamar e dialogar [...] me apaixonei, porque eu percebi que a gente podia dar respostas que o próprio poder público não tinha como dar". 
A continuidade das ações e práticas é outra marca cultural do educador ambiental que atua no $\mathrm{CAB}$, onde muitos estão desde o início da construção do projeto e permanecem atuantes ou, pelo menos, envolvidos em ações pontuais do projeto. Essa trajetória de militância pela causa socioambiental também é forte característica do sujeito ecológico (CARVALHO, 2000, 2012).

Os entrevistados apresentam características de sujeitos que continuam voluntariamente desenvolvendo ações socioambientais. Nesse sentido, EAC3 referiu:

Depois que você desenvolve, que você vê se deu certo, a gente não consegue se desvincular daquilo. Isso é uma coisa muito interessante. Dá vontade de falar: agora não vou trabalhar mais. Muito pelo contrário, tudo o que é daquilo você procura trazer, saber se realmente consegue dar prosseguimento, você pode estar falando para alguém. Se vai beneficiar alguém, você sempre pensa no outro.

Alguns educadores participam do $C A B$ desde sua formação. $A$ entrevistada NA, por exemplo, iniciou como consultora do Ministério do Meio Ambiente para desenvolver no CAB o projeto piloto do PROFEA, posteriormente tendo fundado uma empresa de Educação Ambiental com atuação no programa. Um aspecto apontado pelos entrevistados para tornar a participação e, consequentemente, o processo educativo contínuos foi a motivação gerada pelos encontros de formação do CAB. Em seu depoimento, EAT6 salientou que os participantes do CAB, depois da formação no programa, passaram a ter acesso à informação, pois sabem onde buscar o conhecimento.

Dessa forma, a motivação dos entrevistados se renova com o compartilhamento de informações e com 0 acesso ao conhecimento proporcionado pelo programa, a partir dos encontros de formação, e permanece contínua ao longo do desenvolvimento de suas atividades.

Com a interrupção do FEA em 2017, o grupo de gestores de Educação Ambiental, entrevistado no município de Cascavel, juntamente com colaboradores, está organizando encontros de formação locais para manter sua continuidade. Para eles estas trocas motivam para a ação permanente e permitem o acesso a esse conhecimento por outros sujeitos, ampliando a rede de educadores ambientais. Nesse sentido, EAT5 disse que na escola em que atua faziam "antes" e continuarão fazendo "mesmo sem FEA".

No município de Toledo, a Lei Municipal $n^{\circ}$ 2.223/2016 formaliza a política e o sistema de Educação Ambiental local. Segundo a lei, a Educação Ambiental é um componente essencial e permanente devendo estar presente, de forma articulada, em todos os níveis e modalidades do processo educativo. Constituem princípios e objetivos da política municipal da Educação Ambiental a garantia de continuidade, permanência e articulação do processo educativo com todos os indivíduos, grupos e segmentos sociais. Muito embora nas 
diretrizes internacionais e nacionais da Educação Ambiental, notadamente previstos na Política Nacional de Educação Ambiental (PNEA) e no Programa Nacional de Educação Ambiental (ProNEA), já constem estes princípios e objetivos, houve a preocupação local em legislar acerca do tema, como forma de buscar uma continuidade independentemente de política partidária. Esta lei foi citada pelas gestoras de Educação Ambiental nas entrevistas como uma conquista para efetivar a temática socioambiental como um componente permanente no processo educativo.

Assim, esses educadores ambientais do $C A B$ são sujeitos que se mantém voluntariamente desenvolvendo ações socioambientais e entendem que a política pública de Educação Ambiental é uma conquista decorrente da própria continuidade dada ao trabalho.

\section{Conclusões}

É possível identificar no perfil dos educadores ambientais do $C A B$ entrevistados notadamente a formação em áreas educativas e a motivação intrínseca que decorre da afinidade com a Educação Ambiental, o pensar na coletividade e na alteridade. Além disso, dão continuidade às ações do $\mathrm{CAB}$ e demonstram proximidade e pertencimento a sua comunidade e uma capacidade de aproximar pessoas.

Os educadores ambientais do $\mathrm{CAB}$ entrevistados constituíram seu campo de ação e de liberdade aproximando sujeitos, estendendo sua experiência, associando seu conhecimento à liberdade pessoal e coletiva, construindo para si a identidade de sujeito ecológico que modifica o meio por ter uma crença socioambiental internalizada, desenvolvida em uma trajetória de vida.

Dessa forma, os resultados apontam que os educadores ambientais do $\mathrm{CAB}$ possuem uma motivação intrínseca para desenvolver ações de Educação Ambiental locais e de forma contínua. O CAB como aglutinador de sujeitos é fundamental para estimular os educadores ambientais que já possuem esta motivação intrínseca. Por esse motivo, percebe-se que o programa, premiado pela ONU como melhor programa de gestão de águas no mundo em 2015, motiva e agrupa pessoas previamente sensibilizadas, promovendo e financiando os projetos para que permaneçam em atividade, bem como organizando encontros periódicos de formação continuada para seus participantes. Por fim, pode-se concluir que as parcerias entre entes públicos, privados e sociedade civil são determinantes para esse processo ser participativo e atender aos princípios caracterizadores da Educação Ambiental, os quais são: participação, reflexão, valorização de práticas locais, cidadania, criticidade, solidariedade e dialogia. 


\section{Referências}

BARDIN, L. Análise de conteúdo. Tradução de Luís Antero Reto e Augusto Pinheiro. Lisboa: Edições 70, 1977.

BOFF, L. Um ethos para salvar a Terra. In: CAMARGO, A. et al. Meio ambiente Brasil: avanços e obstáculos pós Rio-92. São Paulo: Estação Liberdade/ISA, p. 49-56, 2002.

CARVALHO, I.C.M. A invenção do sujeito ecológico: sentidos e trajetórias em Educação Ambiental. Porto Alegre: UFRGS, 2000.

CARVALHO, I.C.M. A invenção ecológica: narrativas e trajetórias da Educação Ambiental no Brasil. Porto Alegre: UFRGS, 2002.

CARVALHO, I.C.M. Educação Ambiental: a formação do sujeito ecológico. São Paulo: Cortez, 2012.

CASTELLS, M. A era da informação: economia, sociedade e cultura. São Paulo: Paz e Terra, 2001.

CAB. CULTIVANDO ÁGUA BOA. Informações. Disponível em: $<$ www.cultivandoaguaboa.com.br $>$. Acesso em: fev. 2018.

FREIRE, P. Extensão ou Comunicação? São Paulo: Paz e Terra, 2002.

HEIDEGGER, M. La esencia del habla. De camino al habla. Barcelona: Edicionaes del Serbal, p. 141-194, 1987.

INSTITUTO DAS ÁGUAS DO PARANÁ. Proposta de atualização do enquadramento da Bacia do Paraná 3 (BP3). Cascavel, 2016. Disponível em: $<$ http://www.aguasparana.pr.gov.br/arquivos/File/Parana 3/P01 Definicao curs os dagua a serem enquadrados e Revisao do Daignostico Qualidade Rev 2.pdf>. Acesso em: ago. 2017.

JACOBI, P.R. Educação Ambiental: o desfio da construção de um pensamento crítico, complexo e reflexivo. Educação e Pesquisa, São Paulo, v. 31, n. 2, p. 233-250, mai./ago. 2005.

JACOBI, P.R. Educação Ambiental, cidadania e sustentabilidade. Cadernos de Pesquisa, n. 118, p. 189-205, mar. 2003.

JARA HOLLIDAY, O. Sistematização das experiências: algumas apreciações. In: BRANDÃO, C.R.; STRECK, D.R. (Orgs.). Pesquisa participante: o saber da partilha. Aparecida: Ideias e letras, 2006.

LARROSA BONDÍA, J. Notas sobre a experiência e o saber de experiência. Revista Brasileira de Educação, n. 19, p 20-28, 2002. Disponível em: $<$ http://www.scielo.br/pdf/rbedu/n19/n19a02.pdf >. Acesso em: fev. 2017.

LOUREIRO, C.F. Trajetórias e fundamentos da Educação Ambiental. São Paulo: Cortez, 2006. 
MORAES, R. Mergulhos discursivos: análise textual qualitativa entendida como processo integrado de aprender, comunicar e interferir em discursos. In: FREITAS, J.V.; GALIAZZI, M.C. (Org.). Metodologias Emergentes de Pesquisa em Educação Ambiental. ljuí: Unijuí, 2007.

SATO, M. Formação em Educação Ambiental: da escola à comunidade. In: Panorama da Educação Ambiental no Brasil. Brasília: MEC, 2000. Disponível em: $<$ http://portal.mec.gov.br/secad/arquivos/pdf/educacaoambiental/panorama.pdf >. Acesso em: out. 2017.

SORRENTINO, M. Desafios à Educação Ambiental escolar. In: JACOBI, P. et al. (Orgs). Educação, meio ambiente e cidadania: reflexões e experiências. São Paulo: SMA, 1998.

STRECK, D.R. et al. Educação popular e docência. São Paulo: Cortez, 2014.

TOURAINE, A. Crítica da modernidade. Petrópolis: Vozes, 1999.

TRISTÃO, M. As dimensões e os desafios da Educação Ambiental na sociedade do conhecimento. In: RUSHEINSKY, A. (Org.). Educação Ambiental: abordagens múltiplas. Porto Alegre: Artmed, 2002.

VIEZZER, M.L. Círculos de aprendizagem para a sustentabilidade: caminhada do coletivo educador da Bacia do Paraná III e Entorno do Parque Nacional do Iguaçu 2005-2007. Foz do Iguaçu: ITAIPU Binacional; Ministério do Meio Ambiente, 2007.

ZAKRZEVSKI, S.B. As tendências da educação. In: ZAKRZEVSKI, S.B. A Educação Ambiental na escola: abordagens conceituais. Erechim: Edifapes, 2003. 